\title{
ASSESSMENT OF FUNCTIONAL STATUS OF ELDERLY RESIDING AT OLD AGE HOMES OF PUDUCHERRY
}

\section{Nursing}

R.Gomathy*

\section{Dr. D.Karaline} Karunagari

Ph.D Scholar, Rani Meyyammai College of Nursing, Annamalai University, Annamalainagar, -608002, Tamilnadu, India. ${ }^{*}$ Corresponding Author

Professor, Former Principal, Rani Meyyammai College of Nursing, Annamalai University, -608002, Tamilnadu, India.

\section{ABSTRACT}

Aging is a natural process, which produces a decline in organ function. Functional limitations put the elderly at risk for falls, reduced access to medical services, poor quality of life, declining functional abilities, and negative health outcomes. The present study is aimed to assess the functional status of the elderly residing in old age homes of Puducherry. The descriptive study was conducted among 70 participants aged 60-75 years. The basic demographic data were collected from the study participants followed by physical assessments was done. The functional status of the elderly was assessed using the modified Katz index scale. The results revealed that $30 \%$ of the participants were found moderate impairment in their activities of daily living (ADL). Among the basic ADL activities, the highest percentage of dependence was observed in transferring $(32.86 \%)$, followed by bladder continence (27.14\%), using the toilet (17.14\%), dressing (15.71\%), getting a bath (7.14\%), bowel continence $(5.71 \%)$ and feeding $(4.29 \%)$. Age, hearing, range of motion, and self-reported difficulty in walking were significantly associated with ADL dependency. The study concluded that functional dependence was high among old age home residents requires suitable interventions at the community level.

\section{KEYWORDS}

\section{Activities of daily living, elderly, functional status, Katz scale.}

\section{INTRODUCTION}

Aging is an inevitable and irreversible biological reality, which has its own dynamics, largely beyond human control. Increasing longevity and declining fertility are the key drives for the faster growth of the old age population. According to United Nations Population Fund (UNFPA) report, India's population in 2019 stood at 1.36 billion, growing from 942.2 million in 1994, and 6\% of India's population was aged 65 years and above (World Population 2019 report). Life expectancy at birth was 68.3 years in India which breaks down to 66.9 years for men and 69.9 for women (WHO 2015).

Aging is a natural process, which produces a decline in organ function. This results in subsequent loss of ADL, and chronic illness. ADL is an important indicator to assess the functional status of a person's. ADLs are basic tasks of daily life that most people are used to doing without assistance such as bathing, dressing, toileting, transferring, continence, and feeding. Health issues and aging may make it difficult for the elderly to complete certain everyday self-care tasks that are essential to keep them healthy and safe.

Anandaraj, Prakash, and Vasudevan (2018) studied the prevalence of ADL disability among 245 rural elderly in Puducherry. The results showed $13.9 \%$ of ADL prevalence, and illiteracy, economic dependency, marital status, living arrangement, and sleep problems were significantly associated with ADL disability.

A study from Southeastern Poland found a high prevalence of ADL $(17.13 \%)$ and Instrumental activities of daily living (IADL) (35.75\%) disability, and also observed problems of getting out of bed and moving around $17.54 \%$ of the elderly. The age group was significantly associated with ADLs and IADLs' problems (Cwirlej-SozaNska et al. (2019).

Khan ZA, Singh C, Khan T (2018) reported that $21.4 \%$ and $18 \%$ of elderly people had some form of disability according to the Barthel index and Katz index, respectively. Advanced age and the presence of three or more chronic diseases were significant factors related to physical disability.

The inability to accomplish essential ADL tasks results in dependence on others and/ or the use of mechanical devices to meet their own needs. Loss of functional status is associated with increased risk of institutionalization, stay at home, hospitalization, need for a caregiver, and falls among the elderly and is considered an independent risk factor for mortality.

\section{NEED FOR THE STUDY}

Functional ability among the elderly is one of the important components of well being and its impairment will reduce the quality of life. The threat to functional independence in the elderly arises as a result of physiological changes from the aging process. Lack of functional capacity in each ADL or IADL task can result from any combination of physical problems, memory loss, lack of social resources, or lack of motivation. The determinants of the functional ability of the elderly are the number of chronic conditions, age, sex, physical activity, socioeconomic status, education, and occupation, etc.

Vijaya Kumari S and Surya Prabha M.L (2018) estimated the prevalence and factors influencing functional status limitation among 200 elderly in Kurnool City, Andhra Pradesh. The overall prevalence of ADL and IADL was found to be $68 \%$ and $85 \%$ respectively. Functional limitation was increased with age and those with comorbidities.

A community-based cross-sectional study to estimate the magnitude of functional disability among 350 elderly in Palam village of Delhi. The subjects were assessed for ADL, visual acuity, and hearing by Barthel ADL index scale, Snellen's chart, and whisper test respectively. The study results revealed that the prevalence was $23.1 \%$, and functional disability was more in unmarried /widow /widower group, illiterates, lower socio-economic and financially dependent groups (Kumar D, Rasania S K, and Das R,(2018).

A cross-sectional study was undertaken on ADL and to identify the reasons for admission to old age homes in Nagpur city, Central India. The prevalence of ADL dependency was $21.02 \%$, and also found age increases ADL dependency. No one to look after, strained relationships with family members, and economic constraints were found to be reasons for admission to the old age homes (Jadhao AR, Ghongte PR, Ughade SN,(2017)

Keshari P and Shankar H (2017) reported that the overall prevalence of functional disability was $53.6 \%$. The severity of ADLs restriction was observed in $13.5 \%$ of the subjects and also found that all subjects had independence for bowel continence and lowest for climbing a stair $(47.4 \%)$

Only a few studies were conducted on functional status among the elderly in Puducherry. With this background, an attempt was made to determine the level of functional status among the elderly and its association with selected demographical variables. 
70 elderly participants aged 60-75 years residing at old age homes of Puducherry, India. All participants were informed about the purpose of the study and also written, and informed consent was obtained from them. Socio-demographic data were collected from the study participants followed by physical assessments were carried out. The functional status of the elderly was assessed by using the modified Katz index of independence in the activity of daily living scale. Statistical analysis was carried out using the Statistical Package for Social Sciences (SPSS, version 22) statistical software.

Table 1. Distribution Of Demographic Variables Of Elderly $\quad \mathbf{N}=70$

\begin{tabular}{|c|c|c|c|}
\hline \multicolumn{2}{|l|}{ Demographic variables } & \multirow{2}{*}{\begin{tabular}{|l|} 
No \\
20
\end{tabular}} & \multirow{2}{*}{\begin{tabular}{|l|}
$\%$ \\
$28.57 \%$
\end{tabular}} \\
\hline Age in years & $60-65$ years & & \\
\hline & $66-70$ years & 27 & $38.57 \%$ \\
\hline & $71-75$ years & 23 & $32.86 \%$ \\
\hline \multirow[t]{2}{*}{ Gender } & Male & 27 & $38.57 \%$ \\
\hline & Female & 43 & $61.43 \%$ \\
\hline \multirow[t]{3}{*}{ Religion } & Hindu & 50 & $71.43 \%$ \\
\hline & Christian & 16 & $22.86 \%$ \\
\hline & Muslim & 4 & $5.71 \%$ \\
\hline \multirow[t]{6}{*}{ Educational status } & No formal education & 27 & $38.57 \%$ \\
\hline & Primary education & 17 & $24.29 \%$ \\
\hline & High school education & 16 & $22.86 \%$ \\
\hline & Higher secondary education & 7 & $10.00 \%$ \\
\hline & Diploma/graduate & 3 & $4.29 \%$ \\
\hline & Postgraduate \& above & 0 & $0.00 \%$ \\
\hline \multirow[t]{5}{*}{ Marital status } & Unmarried & 3 & $4.29 \%$ \\
\hline & Married & 34 & $48.57 \%$ \\
\hline & Widow/widower & 31 & $44.29 \%$ \\
\hline & Divorce & 2 & $2.86 \%$ \\
\hline & Separated & 0 & $0.00 \%$ \\
\hline \multirow{3}{*}{$\begin{array}{l}\text { Duration of stay at old } \\
\text { age home }\end{array}$} & Less than one year & 15 & $21.43 \%$ \\
\hline & $1-5$ years & 37 & $52.86 \%$ \\
\hline & 6- 10 years & 18 & $25.71 \%$ \\
\hline \multirow[t]{2}{*}{ Dietary pattern } & Vegetarian & 5 & $7.14 \%$ \\
\hline & Non -Vegetarian & 65 & $92.86 \%$ \\
\hline \multirow[t]{6}{*}{ Leisure activities } & Walking & 20 & $28.57 \%$ \\
\hline & Yoga & 3 & $4.29 \%$ \\
\hline & Household work & 21 & $30.00 \%$ \\
\hline & Watching TV & 18 & $25.71 \%$ \\
\hline & Chatting with others & 8 & $11.43 \%$ \\
\hline & Any other specify & 0 & $0.00 \%$ \\
\hline
\end{tabular}

Table 1 shows that about $38.57 \%, 32.86 \%$ of subjects were aged between $66-70$ years, and 71-75 years, $61.43 \%$ were females and $71.43 \%$ were Hindu. As per literacy status, it was observed that $27(38.57 \%$ ) had no formal education, $48.57 \%$ were married, $52.86 \%$ were staying at old age home for $1-5$ years, $92.86 \%$ were nonvegetarian, $30.00 \%, 28.57 \%$, and $25.71 \%$ of elderly reported that household work, walking and watching as their leisure time activities respectively.

\section{Distribution of Physical Assessment findings of elderly}

The study revealed that $37(53.6 \%), 32(46.4 \%)$ subjects had a BMI of $18.5-24.9 \mathrm{~kg} / \mathrm{m} 2$ and $25.0-29.9 \mathrm{~kg} / \mathrm{m} 2$ respectively. Thirty-five subjects $(50.7 \%)$ had a normal body built, $24(34.8 \%)$ had a vision score of $6 / 8,48(69.6 \%)$ were able to respond well to whisper hearing tests. Fifty-two subjects $(75.4 \%)$ had no weight loss and $8(11.6 \%)$ had lost $1 \mathrm{~kg}$ of weight, $19(27.5 \%)$ had $10-20$ nos. of teeth, $49(71.0 \%)$ had no caries, $62(89.9 \%)$ had no denture, and $52(75.4 \%)$ were able to recall three objects in 5 minutes. Regards to the range of motion, 34 subjects $(49.3 \%)$ had limited movement of the lower limb, 30(43.5\%) subjects found climbing 10 steps or walking one-quarter of a mile with much difficulty, and also observed that $15(21.7 \%)$ subjects were unable to walk one-quarter of a mile or climbing 1- steps. Thirteen subjects $(18.8 \%)$ had musculoskeletal problems (Osteoarthritis \& Osteoporosis), 34(49.3\%) had taken Tab. Calcium and Multivitamin as supplementation.

Table 2. Distribution of Physiological Parameters among elderly

\begin{tabular}{|c|c|c|c|c|c|}
\hline $\begin{array}{c}\text { Physiological } \\
\text { Parameters }\end{array}$ & Mean & SD & Minimum & Maximum & Range \\
\hline Height & 154.46 & 6.70 & 140.0 & 168.0 & 28.0 \\
\hline
\end{tabular}

\begin{tabular}{|c|c|c|c|c|c|}
\hline Weight & 58.19 & 5.67 & 49.0 & 70.0 & 21.0 \\
\hline BMI & 24.38 & 1.57 & 20.7 & 28.5 & 7.8 \\
\hline Pulse rate & 74.40 & 4.16 & 68.0 & 84.0 & 16.0 \\
\hline SBP(lying) & 121.31 & 19.08 & 94.00 & 170.00 & 76.00 \\
\hline DBP(lying) & 77.51 & 12.16 & 60.00 & 110.00 & 50.00 \\
\hline SBP(standing) & 120.17 & 18.67 & 90.00 & 160.00 & 70.00 \\
\hline DBP(standing) & 76.11 & 20.63 & 50.00 & 90.00 & 40.00 \\
\hline
\end{tabular}

Table 2 shows the means score of physiological parameters like height (154.46), weight (58.19), BMI (24.38), pulse rate (74.40), lying SBP (121.31), lying DBP (77.51), SBP (120.17), and standing DBP (176.11).

Table 3. Distribution of elderly according to their ability to perform ADI

\begin{tabular}{|c|c|c|c|c|}
\hline \multirow{2}{*}{ ADL } & \multicolumn{2}{|c|}{ Independence } & \multicolumn{2}{c|}{ Dependence } \\
\cline { 2 - 5 } & $\mathbf{n}$ & $\mathbf{\%}$ & $\mathbf{n}$ & $\mathbf{\%}$ \\
\hline Bathing & 65 & $92.86 \%$ & 5 & $7.14 \%$ \\
\hline Dressing & 59 & $84.29 \%$ & 11 & $15.71 \%$ \\
\hline Toileting & 58 & $82.86 \%$ & 12 & $17.14 \%$ \\
\hline Transferring & 47 & $67.14 \%$ & 23 & $32.86 \%$ \\
\hline $\begin{array}{c}\text { Continence } \\
\text { (Bladder) }\end{array}$ & 51 & $72.86 \%$ & 19 & $27.14 \%$ \\
\hline $\begin{array}{c}\text { Continence } \\
\text { (Bowel) }\end{array}$ & 66 & $94.29 \%$ & 4 & $5.71 \%$ \\
\hline Feeding & 67 & $95.71 \%$ & 3 & $4.29 \%$ \\
\hline
\end{tabular}

Table 3 shows the level of ADL independence including dependence for each activity. Among the basic ADL activities, the highest percentage of dependence was about transferring $(32.86 \%)$, followed by bladder continence $(27.14 \%)$, going to the toilet (17.14\%), dressing $(15.71 \%)$, getting a bath $(7.14 \%)$, bowel continence $(5.71 \%)$ and feeding $(4.29 \%)$

Table 4. Distribution of level of ADL impairment among the elderly $\mathbf{N}=\mathbf{7 0}$

\begin{tabular}{|c|c|c|}
\hline Level of ADL & $\mathbf{N}$ & $\mathbf{\%}$ \\
\hline Totally Dependent $(0)$ & 0 & $0.00 \%$ \\
\hline Severe impairment $(\leq 2)$ & 0 & $0.00 \%$ \\
\hline Moderate impairment $(3-4)$ & 21 & $30.00 \%$ \\
\hline Totally Independent $(5-7)$ & 49 & $70.00 \%$ \\
\hline Total & 70 & $100.00 \%$ \\
\hline
\end{tabular}

Table 4 shows that the majority of subjects $(70 \%)$ were totally independent in meeting their own ADL need, and only $30 \%$ found moderate impairment in their ADL. None of the subjects falls under the category of sever and totally dependent.

Association between levels of functional status with selected demographical variables

The study results revealed that only age in the year had shown statistically significant association with $\operatorname{ADL}(\mathrm{p}=0.01)$, whereas in physical assessments; hearing $(p=.0 .01)$, range of motion $(p=.0 .01)$, and Self reported difficulty in walking one-quarter of a mile or climbing 10 steps $(p=0.01)$ were found a statistically significan association with the level of functional status.

\section{DISCUSSION}

The present study revealed that $30 \%$ of the study participants had moderate impairment in their ADL. The study findings were similar to Burman J (2019) conducted a community-based cross-sectional among 246 geriatric people in a rural area of West Bengal. The results show that $32.4 \%$ were dependent on basic ADL, and age showed a significant association with ADL. However, studies conducted in different parts of India showed a functional dependence; Andhra Pradesh (68\%), Raipur (50.15\%), Varanasi (53.6\%), Tamilnadu (46.84\%), Haryana (37.4\%), Uttar Pradesh (23.4\%), Puducherry (13.9\%), Jammu district (9.54\%), Kerala (8.4\%), and Shimla (5.5\%).

The highest percentage of ADL dependence with transferring (32.86\%), followed by bladder continence (27.14\%), going to the toilet (17.14\%), dressing $(15.71 \%)$, getting a bath $(7.14 \%)$, bowel continence $(5.71 \%)$ and feeding $(4.29 \%)$ in the study. These findings were similar to a study conducted in Andhra Pradesh by Veerapu N et al (2016) were found the highest percentage of dependence for ADL was 
with urinary continence/evacuation (12.7\%), followed by getting a bath $(7.5 \%)$; and in Karnataka study reported about $40.3 \%, 26.7 \%$, $19.0 \%, 17.6 \%, 12.2 \%$, and $11.8 \%$ of the participants' dependence for feeding, toileting, dressing, continence transferring and bathing respectively (Anupama P et al.(2015).

The present study found that age, hearing, range of motion, and selfreported difficulty in walking one-quarter of a mile or climbing 10 steps were significantly associated with dependency for ADL. These findings were similar to Vijaya Kumari S and Surya Prabha M.L (2018) found that functional limitation increased with age and those with comorbidities.In other studies (Sharma D, Mazta SR, Parashar A, 2013), advancing age, poor self-rated health, and ailments namely musculoskeletal problems and cataract significantly associated with functional limitation.

\section{CONCLUSION}

The study concluded that $30 \%$ of the elderly were dependent on basic ADL. Increasing age, hearing, range of motion, and self-reported difficulty in walking were found significantly associated with dependence for ADL. ADL dependence in the elderly has become an important public health problem and health team members should take efforts to initiate the simple physical activity session to limit the progression of functional dependence among the elderly. To face the challenges of elderly population, there is a need to emphasize the primary preventive measures and early diagnosis and treatment of chronic diseases, particularly associated with functional disability.

\section{Financial support and sponsorship}

Nil.

\section{Conflicts of interest}

There are no conflicts of interest.

\section{REFERENCES}

[1] Anandaraj R, Prakash M, Kavita Vasudevan.(2018) Prevalence of disability in activities of daily living among elderly in a rural community of Puducherry. Int J Community Med Public Health, 5(10), 4403-4407.

[2] Cwirlej-SozaNska et al. (2019). Determinants of ADL and IADL disability in older adults in southeastern Poland. BMC Geriatrics, 19:297

[3] Khan ZA, Singh C, Khan T. (2018). Correlates of physical disability in the elderly population of Rural North India (Haryana). J Fam Community, 25,199-204.

[4] Vijaya Kumari S and Surya Prabha M.L (2018). Prevalence and Factors Influencing Functional Status Limitation Among Elderly in Urban Area of Kurnool City; Andhra Pradesh. International Journal of Current Advanced Research, 07(1), 8979-8982.

[5] Kumar D, Rasania S K, and Das R. (2018). A Clinico -Social Study of Functional Disabilities among Elderly in Palam Village of Delhi Indian Journal of Community \& Family Medicine, 4 (01), 47-51.

[6] Jadhao AR, Ghongte PR, Ughade SN. (2017). Activities of daily living amongst inmates of home for aged in Nagpur, Maharashtra, India: a cross sectional study. Int J Res Med Sci, $5,1964-9$.

[7] Keshari P and Shankar H. (2017).Prevalence and spectrum of functional disability of urban elderly subjects: A community-based study from Central India. Journal of family \& community medicine, 24(2), 86-90

[8] Burman J, Sembiah S, Dasgupta A, Paul B, Pawar N, Roy A. (2019). Assessment of poor functional status and its predictors among the elderly in a rural area of West Bengal. J Mid-life Health, 10,123-30

[9] Veerapu $\mathrm{N}$ et al. (2016). Functional dependence among elderly people in a rural community of Andhra Pradesh, South India. Int J Community Med Public Health, 3(7), 1835-1840.

[10] AlamN., SinghS., ShrivastavaN., VermaN., \& Bhawnani D.(2015). Study on functional status and its predictor among elderly population of Raipur city (c.g.), India. Indian Journal of Preventive \& Social Medicine, 46(3-4), 5

[11] Singh P, Gupta RK, Jan R, Shora TN, Raina SK.(2017) Assessing the functional disability of rural elderly population from North-West India using activity of daily living scale: A cross-sectional survey. J Dent Allied Sci, 6, 56-59.

[12] KR Sowmiya, P. Ganesh Kumar, Nagarani. (2015). A study on prevalence and correlates of functional disability among the elderly in rural Tamilnadu. Int J Med Res Rev, 3(4), 430-435.

[13] Gupta P, Mani K, Rai SK, Nongkynrih B, Gupta SK. (2014). Functional disability among elderly persons in a rural area of Haryana. Indian Journal of Public Health, 58(1), $11-16$.

[14] Anupama P, Naik PR, Pracheth R.(2016). Functional assessment of elderly population: a community based cross-sectional study. Int J Med Sci Public Health, 5, 438-442.

[15] Anitha Bhaskar, Manjula V. D, Jose Joseph.(2014). Study on Morbidities and Functional Disabilities of Elderly in Rural Area of Kottayam. Journal of Evolution of Medical and Dental Sciences, 3(37), 21

[16] Sharma D, Mazta SR, Parashar A. (2013). Behavior and lifestyle factors among older persons living in a district of North India. J Med Soc, 27, 61-64. 